Japan. J. Med. Sci. Biol., 36, 273-280, 1983

\title{
STUDIES ON THE IN VITRO ANTIGENICITY TEST OF THE HEPATITIS B SURF ACE ANTIGEN PREPARATION AND ITS RELATIONSHIP TO THE IN VIVO POTENCY ESTIMATE
}

\author{
Haruichi SAITO, Masami KUROKAWA, Takashi TAKAHASHI*, \\ Yoji GOTO* and TAKaSHI HASHIMOTO* \\ Department of Blood Products, National Institute of Health, Kamiosaki, \\ Shinagawa-ku, Tokyo 141, and *The Kitasato Institute, \\ Shirokane, Minato-ku, Tokyo 108
}

(Received July 4, 1983. Accepted July 28, 1983)

\begin{abstract}
SUMMARY: The in vitro method for measuring the antigenicity of the Hepatitis B surface (HBs) antigen devised by our laboratories was applied to the antigenicity estimation of intermediate and final products processes of production of hepatitis B (HB) vaccine. The results showed that the method can widely be used at least for the in process control test of $\mathrm{HB}$ vaccine.
\end{abstract}

\section{INTRODUCTION}

We established a method for potency test of $\mathrm{HB}$ vaccine in guinea pigs, and the potency of each vaccine preparation can be estimated as a relative value to that of a reference vaccine (Takahashi et al., 1982) by applying the parallel line assay method (Finney, 1964). The use of a stable and standardized reference preparation is profitable to minimize possible between-assay variation. However, a potency test in animals is not only troublesome but also inprecise. We already reported an in vitro method for estimation of $\mathrm{HBs}$ antigenicity in radioimmunoassay (RIA) (Saito et al., 1979). By this method, the in vitro antigenicity of an $\mathrm{HBs}$ antigen preparation can also be expressed as a relative value to that of a reference $\mathrm{HBs}$ antigen preparation. It is expected that the estimate obtained by the in vitro method is fairly precise and reproducible.

It is worthwhile studying to find if the in vitro estimate can be consistent with the in vivo one and if there is a certain correlation between the two estimates. By the above confirmation, the in vitro method may be used as a replacement or as a preliminary step for the in vivo potency test in the $\mathrm{HB}$ vaccine production process as well as in developing a vaccine, etc.

In the WHO Minimum Requirements for Hepatitis B Vaccine issued (WHO Expert Committee, 1981), the determination of the titer of HBsAg by a serological test is required, and a quantitative test with a reference preparation is recom-

斎藤晴一・黒川正身 (国立予防衛生研究所血液製剂部)

高橋 隆・後藤暢二・橋本 喬 (北里研究所 港区白金 5-9-1) 
mended to be carried out in parallel, though no specified method is presented.

The present paper describes the results of experiments along this line.

\section{Materials ANd Methods}

HBs antigen: (1) Intact HBs antigen. A purified $\mathrm{HBs}$ antigen was prepared from a source plasma pool from carriers of HBs antigen, subtype adr. The method of purification was described in a previous paper (Takahashi et al., 1982). In brief, precipitation of $\mathrm{HBs}$ antigen at $50 \%$ saturation of ammonium sulfate, removal of human serum protein by flotation through $\mathrm{KBr}$ density gradient, and further purification by rate zonal centrifugation in CsCl- and on sucrose gradients were carried out successively. The purified preparation is hereafter referred to as "HBAgII". (2) Inactivated antigens. The following methods were employed to inactivate HBAgII: (i) Heating at $60 \mathrm{C}$ for $10 \mathrm{hr}$ (hereafter abbreviated as " $\mathrm{H}$ "); (ii) treatment with formalin at a concentration of $1: 2,000$ ("F2000"); (iii) at 1:1,000 ("F1000"); (iv) at 1:330 ("F330"); (v) at $1: 100$ ("F100"); and (vi) treatment of HBAgII by heating at $60 \mathrm{C}$ for $10 \mathrm{hr}$ followed by the formalin treatment at 1:2,000 ("HF2000"). The formalin treatment was carried out always at $37 \mathrm{C}$ for 4 days.

Precipitated $H B$ vaccines: (1) TV-1. A precipitated vaccine was prepared from HF2000 by adding aluminum to $0.3 \mathrm{mg}$ per $\mathrm{ml}$ in a form of aluminum hydroxide gel for use in clinical trials by the Project Team for the Development of HB Vaccine sponsored by the Ministry of Health and Welfare. Its protein content was $31.2 \mu \mathrm{g}$ per ml. The final pH was 6.0. (2) $A-7$. A precipitated HB vaccine named A-7, a product of U.S. National Institute of Allergy and Infectious Diseases (NIAID), was donated to the Project Team by Dr. J. L. Gerin, Georgetown University. The vaccine was an inactivated and alum-precipitated one containing $80 \mu \mathrm{g}$ protein per $\mathrm{ml}$. The method of inactivation was not informed to us.

Solubilization of aluminum gel for use in the RIA test: The aluminum adjuvant was solubilized by adding three or more volumes of $0.45 \mathrm{M}$ sodium citrate and $0.40 \mathrm{M}$ disodium hydrogen phosphate solution containing $0.1 \%$ human serum albumin and by keeping the mixture at $37 \mathrm{C}$ for $30 \mathrm{~min}$.

Method for RIA: The method for RIA was essentially the same to that described by Saito et al. (1979). In brief, Ausria II-125 (Dainabbot Radioisotope Lab., Tokyo) for the solid phase RIA technique was used according to the instruction except the use of the negative control. For dilution of the HBs antigen, physiological saline containing $0.02 \%$ human serum albumin was used (Saito et al., 1979). Each of the twofold dilutions was tested with three or more beads, and cpm was measured with each bead. To avoid possible variations of the test results due to lot-to-lot variation of the test kit, the same kit was used in all tests.

Statistical analyses: $\log _{10}$ net $\mathrm{cpm}$ of the test specimen and the $\log _{10}$ dilution factor were used for statistical analyses. The parallel line assay method 
(Finney, 1964) was applied to the validity test of assay results and in estimation of the relative antigenicity.

\section{Results}

Effects of the Inactivation Treatments on the Antigenicity

The results of the test for antigenicities of HBAgII and six inactivated antigens were plotted against each dose as in Fig. 1. Distinct decreases in the antigenicity were demonstrated for F100 and F330. For F100, the dose-response regression line shifted downward, and its slope became somewhat flatter. Analyses of the data with HBAgII and five inactivated antigens except F100 showed no

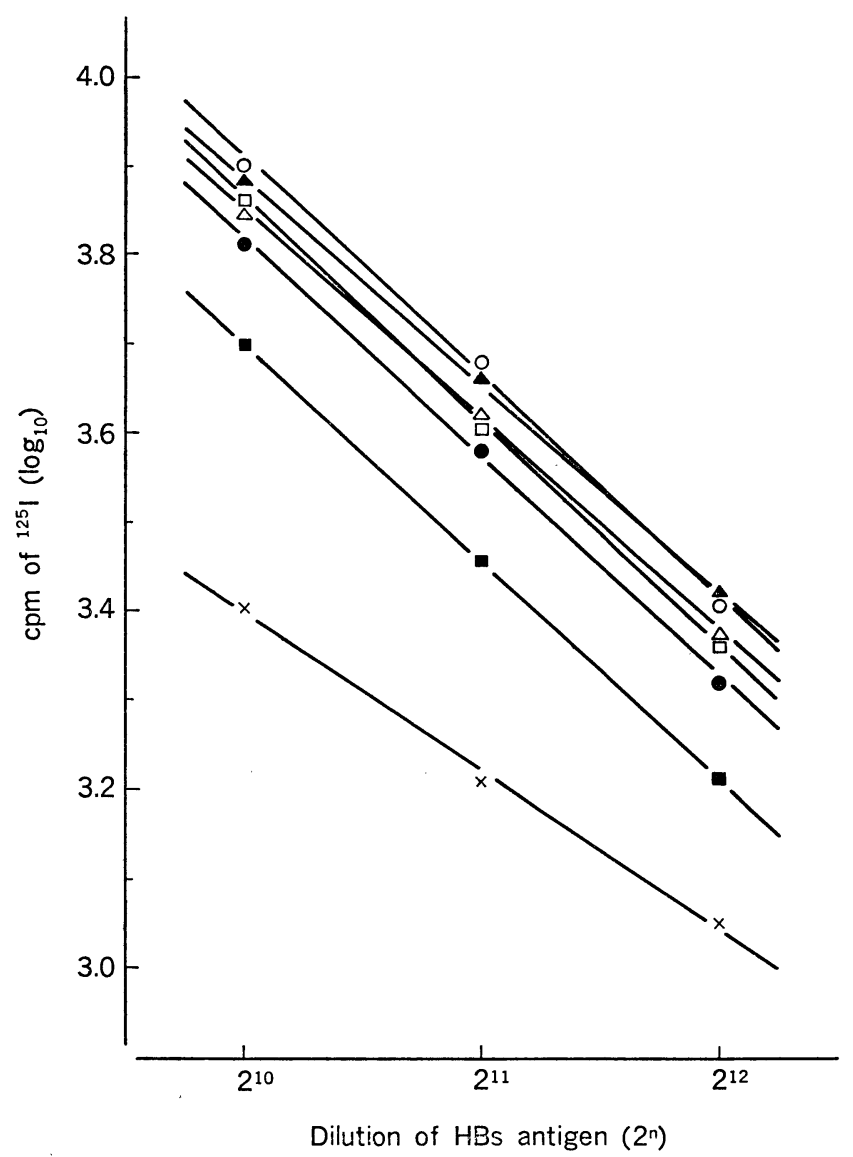

Fig. 1. Dose response regression lines of seven different preparations. Symbol marks represent mean cpm obtained with each three beads.
O: HBAgII (intact); 0 : HF2000, $\triangle:$ H, $\triangle$ : F2000

$\square: F 1000, \mathbf{a}:$ F330, $X: F 100$. 
significant deviations from parallelism among six regression lines (Table I). The regression coefficient (with confidence limits in parentheses) for F100 was 0.593 $(0.735,0.450)$ and distinctly different from the common regression coefficient of $0.807(0.836,0.778)$ for the remaining six preparations. This finding suggests that the treatment with formalin at a concentration of $1: 100$ results in further deterioration of the antigenicity of the $\mathrm{HBs}$ antigen.

No deviation from linearity was observed for the six regression lines and the heteroscedasticity of the variances for the six preparations was not significant (addendum to Table I). The relative antigenicities with their confidence limits of the five inactivated antigens to that of HBAgII are summarized in Table II together with the relative potencies obtained in in vivo experiments by Takahashi et al. (1982). The results of in vitro test appear to reflect fairly well those in vivo ones. The experimental error was much smaller in the in vitro test than the in vivo test and the upper confidence limit of HF2000 was distinctly smaller

\section{TABLE I}

Analysis of variance for the data in Fig. 1

\begin{tabular}{lcccrr}
\hline $\begin{array}{l}\text { Nature of } \\
\text { variation }\end{array}$ & $\begin{array}{c}\text { Sum of } \\
\text { squares }\end{array}$ & $\begin{array}{c}\text { Degrees of } \\
\text { freedom }\end{array}$ & $\begin{array}{c}\text { Mean } \\
\text { square }\end{array}$ & Fo & F $(\alpha=0.05)$ \\
\hline Preparation & 0.25755 & 5 & 0.05151 & 74.652 & 2.477 \\
Regression & 2.10896 & 1 & 2.10896 & 3056.464 & 4.113 \\
Parallelism & 0.00130 & 5 & 0.00026 & 0.377 & 2.477 \\
Linearity & 0.00175 & 6 & 0.00035 & 0.507 & 2.364 \\
\hline Between doses & 2.36956 & 17 & 0.13936 & & \\
Error & 0.02484 & 36 & 0.00069 & & \\
\hline Total & 2.39440 & 53 & & & \\
\hline
\end{tabular}

Homogeneity of variance (Hartley's method)

$\mathrm{F}_{\max }=\mathrm{S}^{2} \max / \mathrm{S}_{\min }=0.00262 / 0.00008=32.1751204$ Hartley's $\mathrm{F}_{\max }(\mathrm{p}=0.05, \mathrm{~K}=18, \mathrm{f}=2)$

TABLE II

Relative values of five inactivated $H B$ s antigen preparations to the intact antigen (HBAgII)

\begin{tabular}{lccccc}
\hline \multirow{2}{*}{$\begin{array}{l}\text { HBs antigen } \\
\text { preparation }\end{array}$} & \multicolumn{2}{c}{ In vitro } & & \multicolumn{2}{c}{ In vivo } \\
\cline { 2 - 3 } \cline { 5 - 6 } & $\begin{array}{c}\text { Relative } \\
\text { antigenicity }\end{array}$ & $\begin{array}{c}\text { Confidence } \\
\text { limits }(0.95)\end{array}$ & & $\begin{array}{c}\text { Relative } \\
\text { potency }\end{array}$ & $\begin{array}{c}\text { Confidence } \\
\text { limits }\end{array}$ \\
\hline HBAgII & 1.000 & & & 1.000 & \\
HF2000 & 0.804 & $0.844,0.765$ & & 0.795 & $1.162,0.544$ \\
H* & 0.888 & $0.950,0.830$ & & 0.721 & $1.411,0.601$ \\
F2000** & 0.983 & $1.051,0.919$ & & 1.165 & $1.700,0.798$ \\
F1000** & 0.862 & $0.922,0.806$ & & 0.683 & $1.060,0.440$ \\
F330** & 0.558 & $0.579,0.520$ & & 0.556 & $0.862,0.359$ \\
\hline
\end{tabular}

* Heated at $60^{\circ} \mathrm{C}$ for $10 \mathrm{hr}$.

** Inactivated with formalin at concentrations of $1: 2,000,1: 1,000$ and $1: 330$. 
than 1.0, suggesting that the combined treatment induced a certain deterioration in the antigenicity of $\mathrm{HBs}$ antigen. The confirmation experiments are presented below. The results with $\mathrm{F} 1000$ and $\mathrm{H}$ suggest also that slight deterioration was induced by the treatments. No test was carried out to confirm this notion.

\section{Effect of a Combined Treatment by Heating and with Formalin}

The Project Team decided to employ a combined treatment for inactivation to secure the safety of the vaccine to be used by the Team (Takahashi et al., 1982). The in vivo tests suggested that the combined treatment might have affected the potency to a certain extent (Takahashi et al., 1982). Therefore, the effect of the combined treatment on the in vitro antigenicity was assessed. The tests were repeated with five independently prepared materials and the results confirmed the above notion. An example is plotted in Fig. 2. The regression lines appeared to be no problem in parallelism and linearity assessment and the relative antigenicity was distinctly lower for HF2000 than for HBAgII. The five relative antigenicities were distributed between 0.496 and 0.951 , while relative potencies between 0.435 and 0.795 (Table III). Some of the differences among five relative antigenicities were statistically significant, suggesting that the effect of inactivation process is not always constant. However, the difference was too small to be detected by the in vivo potency test.

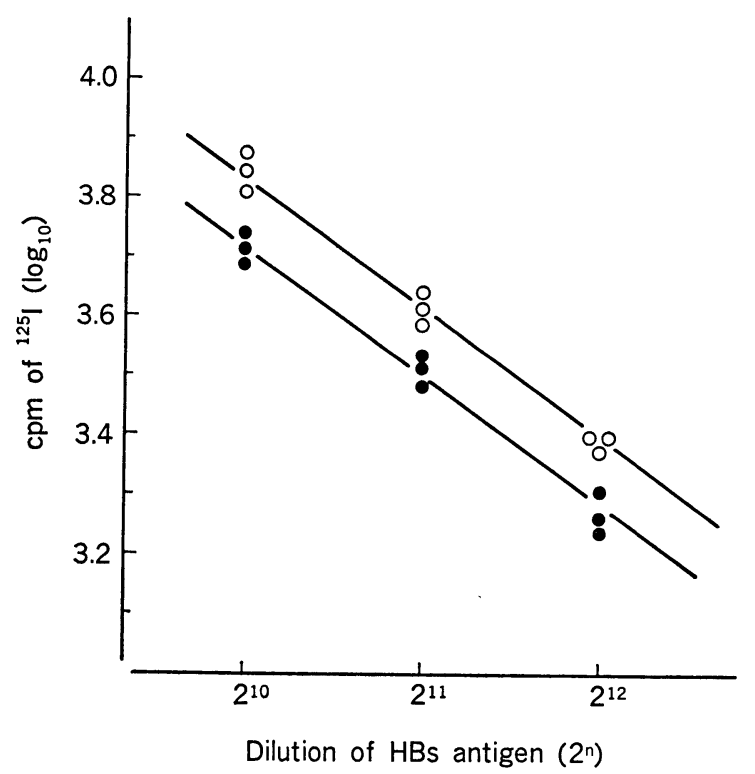

Fig. 2. Dose response regression lines of intact (HBAgII) and inactivated antigens (HF2000).

O: HBAgII, ๑ : HF2000. 
TABLE III

Relative values of inactivated antigen (HF2000) to intact antigen (HBAgII)

\begin{tabular}{|c|c|c|c|c|}
\hline \multirow{2}{*}{$\begin{array}{l}\text { Experiment } \\
\text { No. }\end{array}$} & \multicolumn{2}{|c|}{ In vitro } & \multicolumn{2}{|c|}{ In vivo } \\
\hline & $\begin{array}{c}\text { Relative } \\
\text { antigenicity }\end{array}$ & $\begin{array}{c}\text { Confidence } \\
\text { limits }(0.95)\end{array}$ & $\begin{array}{l}\text { Relative } \\
\text { potency }\end{array}$ & $\begin{array}{c}\text { Confidence } \\
\text { limits }(0.95)\end{array}$ \\
\hline 1 & 0.496 & $0.526,0.467$ & 0.435 & 0.606 .0 .275 \\
\hline 2 & 0.691 & $0.743,0.640$ & 0.610 & $0.941,0.376$ \\
\hline 3 & 0.733 & $0.788,0.678$ & 0.622 & $0.900,0.445$ \\
\hline 4 & 0.951 & $1.006,0.898$ & 0.635 & $0.932, \quad 0.433$ \\
\hline 5 & 0.804 & $0.844,0.765$ & 0.795 & $1.162,0.544$ \\
\hline
\end{tabular}

The Relative Antigenicity of TV-1 to that of HF2000

The in vitro antigenicity test was applied to the final product of the precipitated $\mathrm{HB}$ vaccine, TV-1. As it is known that the aluminum gel disturbes the antigenicity test in RIA, a method for solubilization of the gel was devised. The solution mentioned in Materials and Methods was found to be effective in our system.

Table IV shows the relative antigenicity of solubilized TV-1 to that of HF2000, prepared so as to contain the HBs antigen at the concentration equal to that of TV-1. Each experiment was carried out with three separately solubilized materials. The relative antigenicities were nearly 1.0 in all the three experiments, indicating that the results were fairly reproducible and this procedure is expected to yield reliable results. The results also showed that the HBs antigenicity was not affected by aluminum gel precipitation followed by solubilization.

TABLE IV

Relative antigenicities of solubilized TV-1 to HF2000

\begin{tabular}{ccc}
\hline $\begin{array}{c}\text { Experiment } \\
\text { No. }\end{array}$ & $\begin{array}{c}\text { Relative } \\
\text { antigenicity }\end{array}$ & $\begin{array}{c}\text { Confidence limits } \\
(0.95)\end{array}$ \\
\hline 1 & 0.995 & $1.036,0.954$ \\
2 & 1.023 & $1.098,0.953$ \\
3 & 0.961 & $1.031,0.896$ \\
\hline
\end{tabular}

\section{Relative Antigenicity of $A-7$ to that of $T V-1$}

Lastly, the antigenicities of the solubilized TV-1 and the solubilized A-7 were compared (Fig. 3). No significant deviations from the linearity and parallelism of the regression lines were demonstrated. The antigenicity of A-7 relative to that of TV-1 is presented in Table $\mathrm{V}$ together with its relative potency obtained by in vivo experiments (Takahashi et al., 1982). Though the relative antigenicity and the relative potency were 2.398 and 2.842, respectively, the corrected relative values based on the ratio of the protein content of TV-1 to that of A-7 


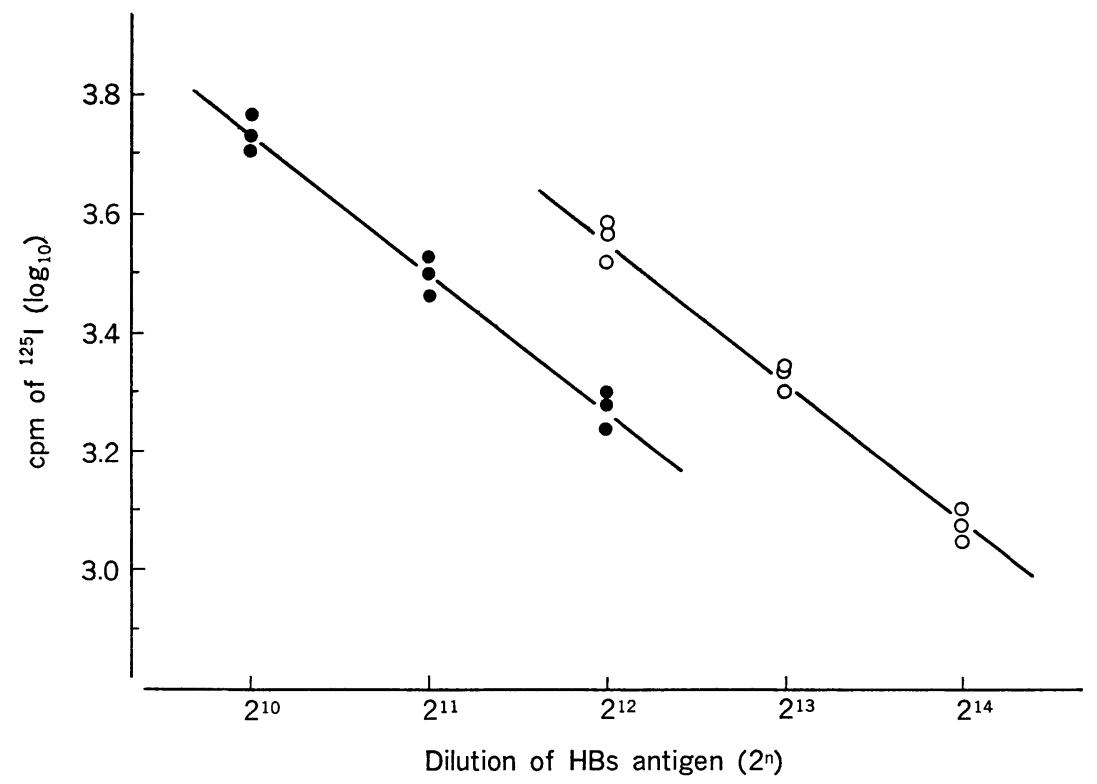

Fig. 3. Dose response regression lines of solubilized TV-1 and solubilized A-7.

$0:$ A-7,

: TV-1.

TABLE V

Relative value of $A-7$ (NIAID vaccine) to $T V-1^{*}$

\begin{tabular}{ccccccc}
\hline & \multicolumn{2}{c}{ In vitro } & & \multicolumn{2}{c}{ In vivo } \\
\cline { 2 - 3 } \cline { 5 - 6 } & $\begin{array}{c}\text { Relative } \\
\text { antigenicity }\end{array}$ & $\begin{array}{c}\text { Confidence } \\
\text { limits }(0.95)\end{array}$ & & $\begin{array}{c}\text { Relative } \\
\text { potency }\end{array}$ & $\begin{array}{c}\text { Confidence } \\
\text { limits }(0.95)\end{array}$ \\
\hline$(1)^{* *}$ & 2.398 & $2.563,2.244$ & & 2.842 & $4.612,1.644$ \\
$(2)^{* * *}$ & 0.935 & $1.000,0.875$ & & 1.108 & $1.802,0.642$ \\
\hline
\end{tabular}

* Protein content: TV-1 $31.2 \mu \mathrm{g} / \mathrm{ml}, \mathrm{A}-780 \mu \mathrm{g} / \mathrm{ml}$.

Ratio in the protein content: TV-1/A-7=1.000/2.564.

** Relative values of the final product before correction.

*** Relative values corrected by the ratio in the protein content.

were 0.935 and 1.108 , respectively, showing that the antigenicity and the potency of the two products are almost equal.

\section{Discussion}

It is well known that the in vitro antigenicity usually does not reflect the in vivo potency with diphtheria or tetanus toxoid. Contrary to these experiences, the present finding with HBs antigen showed that the in vitro data run almost parallel with the in vivo ones. It seems promising that an inexpensive, convenient and precise in vitro method will replace the in vivo potency test in the 
vaccine production process and in research of vaccines.

The inactivation with formalin at a concentration higher than 1:330 appeared to affect the in vivo potency. This was confirmed by the in vitro method. Furthermore, the rate of decrease in the in vitro antigenicity was fairly close to that in the in vivo potency.

It must be pointed out that quite similar results were obtained with our precipitated vaccine and an NIAID vaccine not only in the in vivo potency test but also in the in vitro antigenicity test, although these vaccines were produced independently and our vaccine received such an inactivation treatment that deteriorating both the antigenicity and the potency to a certain extent.

\section{Acknowledgement}

This work was carried out for the Project Team for the Development of HB Vaccine (Chairman: Prof. Dr. T. Oda) and supported by a grant-in-aid from the Ministry of Health and Welfare.

\section{REFERENGES}

Finney, D. J. (1964): Statistical Method in Biological Assay. 2nd ed. Charles Griffin, London. $661 \mathrm{p}$.

Saito, H., Ishida, S., Yasuda, J., Kurokawa, M., Nagai, T. and Takahashi, T. (1979): Application of the parallel line bioassay method to quantitative determination of $\mathrm{HBs}$ antigen in radioimmunoassay. Japan. J. Med. Sci. Biol., 32, 47-52.

Takahashi, T., Saito, H., Kurokawa, M., Yasuda, J. And Hashimoto, T. (1982): Studies on the potency test of $\mathrm{HB}$ vaccine by the parallel line assay method in guinea pigs. Japan. J. Med. Sci. Biol., 35, 53-62.

W.H.O. (1981): Thirty-first Report of WHO Expert Committee on Biological Standardization. WHO Tech. Rep. Ser., No. 658, 131-156. 